Fatimah, Hanif, Muhammad, Taufiqur, Yusril

Pengaruh Kualitas Pelayanan Terhadap Kepuasan Nasabah PT Pegadaian Area

\title{
PENGARUH KUALITAS PELAYANAN TERHADAP KEPUASAN NASABAH PT. PEGADAIAN (PERSERO) AREA SURABAYA 2
}

\author{
Fatima Nur Azizia \\ Universitas Islam Negeri Sunan Ampel Surabaya \\ nuraziziaf@gmail.com \\ Hanif Shiddiqi Akbar \\ Universitas Islam Negeri Sunan Ampel Surabaya \\ sun.98.breaker@gmail.com \\ Muhammad Dzikri \\ Universitas Islam Negeri Sunan Ampel Surabaya \\ muhammaddzikri777@gmail.com \\ Taufiqur Rohman \\ Universitas Islam Negeri Sunan Ampel Surabaya \\ taufiqurrohman814@gmail.com \\ Yusril Alfalah Rilando \\ Universitas Islam Negeri Sunan Ampel Surabaya \\ alfalahyusril@gmail.com
}

\begin{abstract}
This study aims to examine the effect of service quality on customer satisfaction at PT. Pegadaian (Persero) Surabaya Area 2. The research method used is quantitative research methods using linear regression analysis techniques, validity, reliability and normality tests, and hypothesis testing using the $T$ test and $F$ test, which later the data will be processed using Statistical Process Social Science software (SPSS). The object of this research is the customers of PT. Pegadaian (Persero) Surabaya Area 2, amounting to 100 people while the determination of the sample uses the Non Probability Sampling technique with a 5 Point Linkert measurement scale. The results showed that there was a significant relationship between service quality and the level of customer satisfaction, this was evidenced by the results of the T test analysis with a positive significance level of $0.00<0.05$ because the $p$ value <0.05 then Ho was rejected and Ha was accepted. States that there is a positive effect of service quality on customer satisfaction levels. And the results of the F test shows $F$ count $(23,992)$ with a significance level of 0,000 $<0.05$, it can be stated that there is an influence between the variable service quality and customer satisfaction. So that if a conclusion is drawn, there is a relationship between service quality and customer satisfaction at PT. Pegadaian (Persero) Surabaya Area 2.
\end{abstract}

Keywords : Customer's Satisfaction, Service Quality and Pawnshop. 


\begin{abstract}
Abstrak
Penelitian ini bertujuan untuk menguji pengaruh kualitas pelayanan terhadap kepuasan nasabah PT. Pegadaian (Persero) Area Surabaya 2. Metode penelitian yang digunakan adalah metode penelitian kuantitatif menggunakan teknik analisis regresi linear, uji validitas, reabilitas dan normalitas, serta uji hipotesis menggunakan uji $T$ dan uji $F$ yang nantinya data akan diolah menggunakan software Statistical Process Social Science (SPSS). Objek penelitian ini adalah nasabah PT. Pegadaian (Persero) Area Surabaya 2 yang berjumlah 100 orang sedangkan penentuan samplenya menggunakan teknik Non Probability Sampling dengan skala pengukuran Linkert 5 Point. Hasil penelitian menunjukkan bahwa ada hubungan yang signifikan antara kualitas pelayanan dan tingkat kepuasan nasabah, hal ini dibuktikan dengan hasil analisis Uji T dengan tingkat signifikansi positif sebesar 0,00< 0,05 karena nilai $p<0,05$ maka Ho ditolak dan Ha diterima yang menyatakan terdapat pengaruh positif kualitas pelayanan terhadap tingkat kepuasan nasabah. Serta hasil dari Uji F menunjukkan F Hitung $(23,992)$ dengan tingkat signifikansi sebesar 0,000 < 0,05 maka dapat dinyatakan bahwa terdapat pengaruh antara variabel kualitas pelayanan dan kepuasan nasabah. Sehingga jika ditarik kesimpulan maka terdapat hubungan antara kualitas pelayanan dengan kepuasan nasabah pada PT. Pegadaian (Persero) Area Surabaya 2.

Kata Kunci : Kepuasan Pelanggan, Kualitas Pelayanan dan Pegadaian.
\end{abstract}

\title{
PENDAHULUAN
}

Aktifitas perekonomian di suatu negara tidak akan bisa lepas dari lembaga keuangan. Lembaga keuangan dalam aktifitas perekonomian memiliki peran strategis yaitu sebagai pihak yang dapat menghimpun serta menyalurkan dana masyarakat secara efektif demi tercapainya taraf hidup masyarakt yang layak dan sejahtera. Lembaga keuangan merupakan suatu badan penghimpun dana masyarakat yang kemudian akan disalurkan untuk pendanaan. Dalam perkembangannya lembaga keuangan di Indonesia dibedakan menjadi dua jenis yaitu lembaga keuangan bank dan lembaga keuangan bukan bank yang keduanya berperan penting terhadap distribusi keuangan di masyarakat. Salah satu bentuk lembaga keuangan bukan bank yang banyak beredar di tengah masyarakat adalah pegadaian.

Adapun salah satu contoh lembaga keuangan bukan bank adalah pegadaian,dimana merupakan badan yang bergerak dibidang pelayanan jasa peminjaman dana dengan cara menggadaikan barang sebagai jaminannya. PT. Pegadaian (Persero) adalah sebuah perusahaan milik pemerintah yaitu BUMN Indonesia yang usaha intinya adalah bidang jasa peminjaman uang kepada para nasabahnya yang berasaskan hukum gadai. Seiring perkembangan zaman banyak pesaing dalam bidang serupa yang muncul, sehingga kantor pusat dan cabang meluas kebeberapa daerah seperti pada PT. Pegadaian (Persero) Area Surabaya 2

Mekanisme pelayanan PT. Pegadaian (Persero) sendiri adalah pemberian pinjaman kepada nasabah dengan suatu jaminan tersebut kemudian akan dihitung nilainya oleh pihak pegadaian dan dana akan diberikan kepada nasabah sesuai dengan nilai yang terkandung di barang gadaian tersebut. Nasabah akan diberikan tenggang waktu yang dapat digunakan untuk menebus barang yang telah digadaikan tersebut, namun apabila tenggang waktu tersebut sudah terlewat maka barang akan dilelang oleh pihak pegadaian dan tidak dapat ditebus lagi oleh nasabah selaku peminjam. Selain pemberian layanan melalui gadai barang, pegadaian sendiri memberika pilihan layanan lainnya seperti penawarkan jasa pinjaman uang secara online, tambahan tenor pelunasan uang gadai dan mengadakan lelang barang murah. 
Dengan gadai barang sebagai layanan utama dan bentuk-bentuk pelayanan lainnya yang semakin beragam, mendorong nasabah pegadaian untuk melakukan transaksi pada lembaga tersebut sesuai dengan kebutuhan masing-masing. Berbagai layanan yang diberikan serta usaha untuk peningkatan kualitas pelayan diberikan kepada nasabah untuk mencapai kepuasan nasabah sehingga tetap melakukan transaksi pada pegadaian atau menarik minat nasabah yang baru. Untuk mengetahui kepuasan nasabah tersebut, maka penelitian ini akan menggunakan judul "Pengaruh Kualitas Pelayanan Terhadap Kepuasan Pelanggan di PT. Pegadaian (Persero) Area 2 Surabaya".

\section{KAJIAN PUSTAKA DAN PENGEMBANGAN HIPOTESIS}

\section{Kualitas Pelayanan}

Salah satu hal terpenting yang harus selalu dijaga dalam perusahaan jasa adalah kualitas pelayanan yang disajikan pada konsumennya. Perusahaan jasa harus berusaha untuk memenuhi semaksimal mungkin tuntutan yang dilayangkan oleh konsumen karena bagaimanapun kualitas pelayanan akan berdampak dalam jangka panjang terhadap keberlangsungan hidup perusahaan. Oleh karena itu perusahaan apapun terutama yang bergerak dibidang jasa harus memperhatikan bagaimana tingkat kualitas pelayanan yang mereka berikan kepada konsumennya selama ini.

Kualitas didefinisikan sebagai bagaimana sifat suatu produk atau jasa secara menyeluruh yang dadpat berpengaruh terhadap kepuasan suatu kebutuhan baik itu yang dinyatakan secara langsung maupun yang tidak dinyatakan secara langsung. Sedangkan pelayanan didefinisikan sebagai segala bentuk usaha yang dilakukan oleh suatu pihak dalam bentuk pemberian bantuan kepada pihak lain baik berupa materi ataupun yang tidak berupa materi dengan tujuan agar dapat meringankan beban pihak yang mendapat pelayanan tersebut. Selain itu pelayanan dapat didefinisikan juga sebagai suatu kinerja yang diberikan kepada pihak lain dengan tujuan membantu meringankan beban pihak tersebut.

Kualitas pelayanan didefinisikan sebagai suatu tingkat keunggulan dengan tingkat standar tertentu yang dibentuk oleh perusahaan atau organisasi dengan tujuan untuk memenuhi harapan dan keinginan konsumen. Hal inilah yang berusaha untuk diwujudkan oleh perusahaan karena akan sangat berpengaruh terhadap bertahannya konsumen lama dan bertambahnya konsumen baru. Pendapat lain menyatakan bahwa kualitas pelayanan adalah besarnya perbedaan yang didapatkan konsumen antara harapan yang mereka inginkan dengan pelayanan yang mereka dapatkan. Dalam definisi ini tentu kualitas pelayanan akan dinyatakan memuaskan apabila memenuhi harapan konsumen dan mengecewakan apabila tidak memenuhi harapan konsumen. Terdapat lima karakteristik yang dapat digunakan dalam mengevaluasi kualitas pelayanan yaitu sebagai berikut:

1. Daya tanggap (Responsive) merupakan suatu respon atau tanggapan karyawan dalam melayani konsumen serta memberikan bantuan yang cepat dan tanggap.

2. Kehandalan (Reliability) merupakan kemampuan karyawan dalam memberikan jasa yang dijanjikan dengan akurat dan terpercaya.

3. Jaminan (Assurance) merupakan kemampuan karyawan meliputi pengetahuan terhadap produk yang dipasarkan secara tepat, berkualitas, santun, memberikan pelayanan, ketrampilan dan informasi yang optimal.

4. Perhatian (Emphaty) merupakan kemampuan karyawan dalam memberikan perhatian secara pribadi atau individual kepada nasabah.

5. Kemampuan fisik (Tangibles) adalah segala bentuk penampilan fisik meliputi peralatan, media komunikasi dan hal pendukung lainnya yang berwujud. 


\section{Kepuasan Nasabah}

Kepuasan nasabah atau kepuasan konsumen dapat didefinisikan sebagai sejauh mana produk atau jasa dapat memenuhi harapan yang diberikan oleh konsumen. Apabila produk atau jasa yang ditawarkan oleh perusahaan memiliki kinerja yang lebih rendah dibandingkan dengan harapan yang diberikan oleh konsumen maka konsumen akan merasa kecewa terhadap produk atau jasa yang ditawarkan oleh perusahaan, dan sebaliknya apabila produk atau jasa yang ditawarkan oleh perusahaan memiliki kinerja yang lebih baik dari harapan konsumen tentu konsumen akan merasa puas dan bahagia dengan produk atau jasa yang ditawarkan perusahaan.

Kepuasan dan ketidakpuasan konsumen terhadap produk atau jasa yang ditawarkan oleh perusahaan tentu akan memengaruhi keputusan pembelian selanjutnya. Jika konsumen merasa puas dengan produk atau jasa yang ditawarkan oleh perusahaan tentu konsumen akan memiliki peluang lebih tinggi untuk melakukan pembelian kembali di masa yang akan datang bahkan bisa jadi konsumen yang puas akan mengajak sanak, kerabat dan sahabatnya untuk melakukan pembelian juga pada produk atau jasa yang ditawarkan perusahaan. Sebaliknya konsumen yang tidak puas cenderung enggan untuk kembali menggunakan produk atau jasa yang ditawarkan oleh perusahaan bahkan bisa saja mengajak sanak, sahabat dan kerabatnya untuk beralih ke produk atau jasa lain yang dianggap lebih baik.

Dengan banyaknya perusahaan dengan bidang usaha yang sejenis membuat dunia pemasaran semakin keras dalam artian perusahaan harus memutar otak untuk menggaet hati pelanggan dari banyaknya produk atau jasa pesaing yang ditawarkan perusahaan lain. Hal ini berbeda sekali dengan zaman ketika tidak banyak perusahaan yang menawarkan produk atau jasa yang sejenis sehingga konsumen dipaksa untuk membeli produk atau jasa standar yang dimiliki perusahaan tanpa bisa menuntut perusahaan untuk membuat produk atau jasa dengan kualitas yang lebih baik karena terbatasnya barang alternatif. Jika perusahaan dapat memberikan produk atau jasa yang melebihi harapan konsumen tentu akan terjadi kepuasan konsumen yang cirinya adalah sebagai berikut ini:

1. Cenderung akan melakukan pembelian ulang.

2. Memiliki sifat loyal terhadap segala produk atau jasa yang ditawarkan perusahaan.

3. Menyebarkan informasi positif mengenai produk yang ditawarkan oleh perusahaan.

4. Enggan untuk memberikan perhatian terhadap produk atau jasa perusahaan lain.

5. Kurang memberi perhatian pada harga.

6. Memberikan masukan mengenai hal yang perlu di perbaiki dari produk atau jasa yang ditawarkan oleh perusahaan.

\section{KERANGKA KONSEPTUAL}

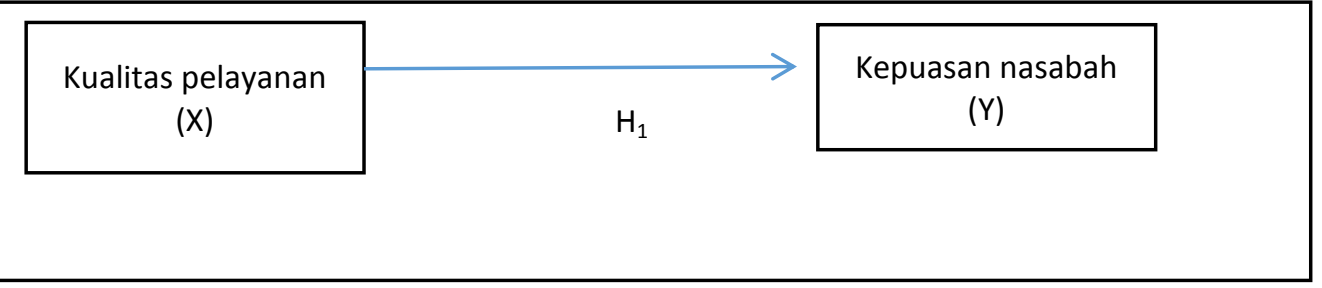


Fatimah, Hanif, Muhammad, Taufiqur, Yusril

Pengaruh Kualitas Pelayanan Terhadap Kepuasan Nasabah PT Pegadaian Area

\section{HIPOTESIS}

Dari gambar diatas dapat dijelaskan bahwa variabel kualitas pelayanan yang terdiri didalamnya sebagai berikut : daya tanggap (Responsive), kehandalan (Reliability), Jaminan (Assurance), perhatian (Emphaty) dan kemampuan fisik (Tangible) memiliki hipotesis pada penelitian ini adalah :

$\mathrm{H}_{1} \quad$ : Kualitas pelayanan berpengaruh signifikan terhadap kepuasan nasabah PT Pegadaian (Persero) Area Surabaya 2

$\mathrm{H}_{0} \quad$ : Kualitas pelayanan tidak berpengaruh terhadap kepuasan nasabah PT Pegadaian (Persero) Area Surabaya 2

\section{METODE PENELITIAN}

Jenis penelitian ini adalah penelitian kuantitatif. Objek penelitian ini adalah Nasabah PT. Pegadaian (Persero) area Surabaya 2. Teknik pengumpulan data dilakukan dengan cara memberikan kuisioner menggunakan google form kepada 100 responden. Kualitas pelayanan sebagai variabel $\mathrm{X}$ dan kepuasan nasabah sebagai variabel $\mathrm{Y}$.

\section{HASIL DAN PEMBAHASAN}

\section{Populasi dan Sampel}

Penentuan responden yang dipilih sebagai sampel penelitian dalam penelitian ini didasarkan pada acuan Non probability sampling dimana responden yang digunakan adalah nasabah PT. Pegadaian baik nasabah lama maupun yang baru bergabung, dimana jumlah populasi telah diketahui sehingga dalam penerapanya maka dihitung dengan ukuran rumus slovin. Adapun rumus slovin yang diterapkan untuk mengukur responden yang akna digunakan adalah jumlah nasabah tetap PT. Pegadaian berjumlah 834 orang sedangkan kunjungan setiap bulannya diperkirakan ada 126 orang sehingga dengan asusmsi tersebut didapat jumlah populasi sebanyak 1000 orang dengan perhitungan sebagai berikut :

$$
\begin{gathered}
\mathrm{N}=\frac{\mathrm{N}}{1+n e^{2}} \\
\mathrm{~N}=\frac{1000}{1+\left(1000 \times 10 \%^{2}\right)}=91 \text { dibulatkan menjadi } 100 \text { responden }
\end{gathered}
$$

Maka setelah terhitung jumlah dari sampel penelitiannya sebanyak 100 responden ,penelitian ini menggunakan jenis kuota sampling, karena penelitain ini harus mendapatkan sebanyak 100 responden yang telah ditetapkan berdasarkan perhitungan rumus. Pengumpulan data dilakukan dengan berkelompok dengan 5 orang pengumpul data, sehingga setiap anggota kelompok mengumpulkan 20 responden sebagai sampel.

\section{Proses Penelitian}

Instrumen penelitian yang diandalkan secara langsung dari sumber yang kredibel berdasarkan instrumen asli Servqual. Serrvqual adalah sebuah pedoman acuan kuisioner yang digunakan utuk mengukur kualitas jasa dan instrumen ini telah dijelasakan rinci oleh Zeithmal, Parasuraman dan Berry tahun 1980 yang memproyeksikan indikator dari variabel 
Fatimah, Hanif, Muhammad, Taufiqur, Yusril

Pengaruh Kualitas Pelayanan Terhadap Kepuasan Nasabah PT Pegadaian Area

Surabaya 2

Jurnal MANOVA Volume IV Nomor 1, P ISSN : 2685-4716, E ISSN : 2746-282X

kualitas pelayanan. Instrumen Ini dijadikan bahan awal dalam menggali dan mengumpulkan data primer melalui responden dengan kuisioner skala pengukuran Likert 5 Point. Skala pengukuran ini diklasifikasikan menjadi lima skala dengan rincian perolehan skor Nilai (1) untuk sangat tidak setuju hingga (5) untuk kategori skor sangat Setuju.

\section{Sumber Data Penelitian}

Sumber data Penelitian yang diperoleh secara langsung dari sumber aslinya yang berupa penjajakan sebelum peneltian diadakan yakni wawancara dengan kepala kantor cabang PT. Pegadaian (Persero) area Surabaya 2 maupun hasil pengambilan data dalam bentuk kuisioner. Dalam penelitian ini dibutuhkan setidaknya responden sebanyak 100 orang kuisioner yang sesuai dengan kriteria terkait penelitian yang dilakukan. Keterangan responden dalam penelitian yang ada pada kuisioner adalah sebagai berikut:

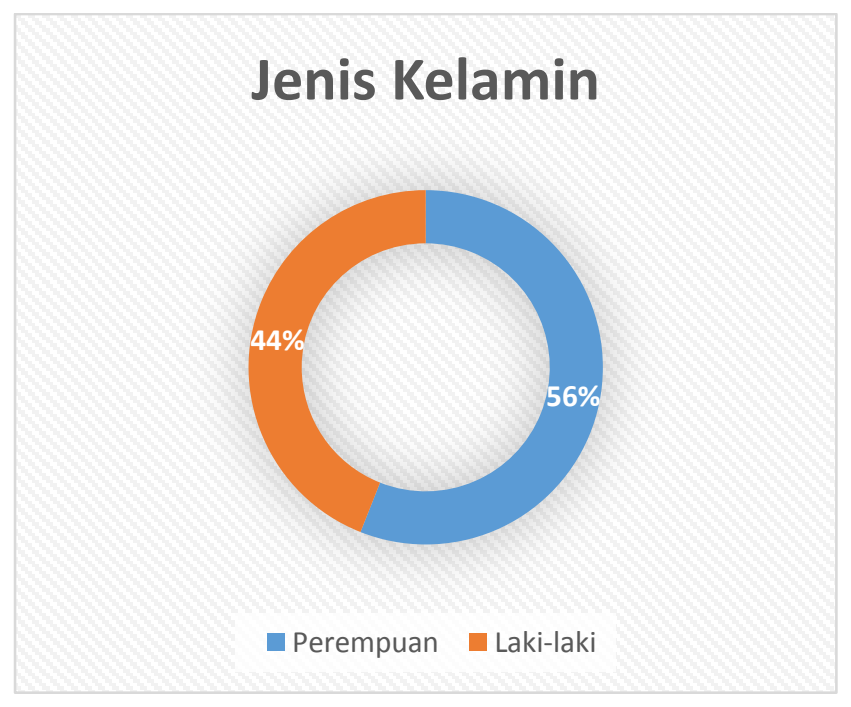

Gambar 1. Jenis Kelamin Responden

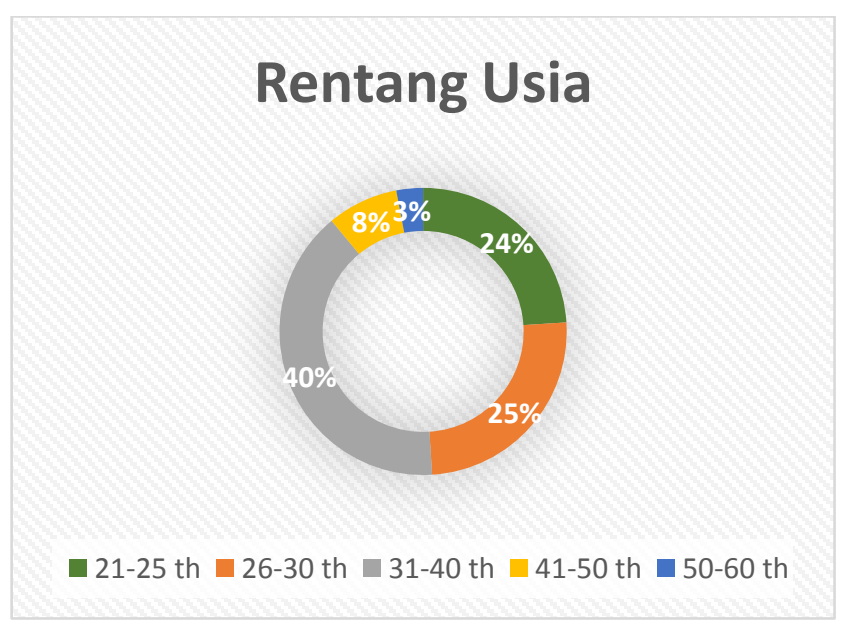

Gambar 2. Rentang Usia Responden 
Fatimah, Hanif, Muhammad, Taufiqur, Yusril

Pengaruh Kualitas Pelayanan Terhadap Kepuasan Nasabah PT Pegadaian Area

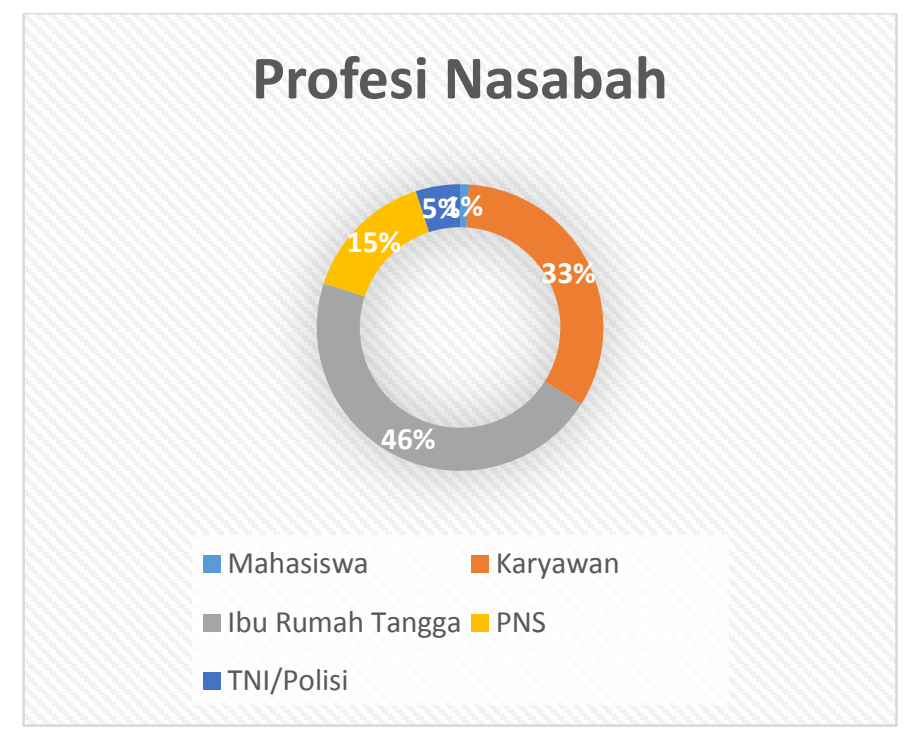

.Gambar 3. Profesi Nasabah

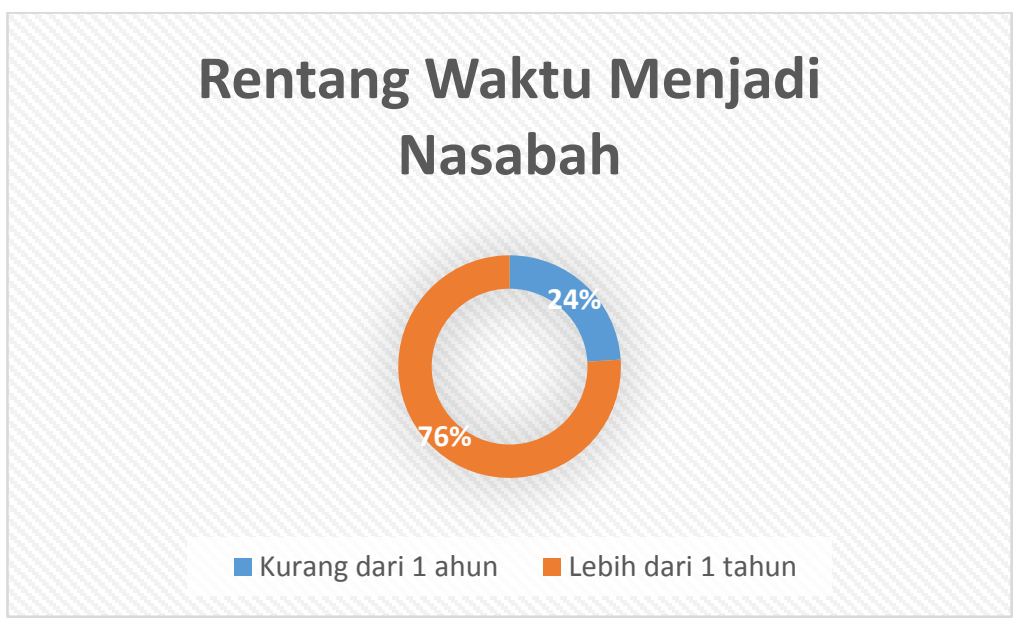

\section{Uji Analisis Regresi Linear Sederhana}

Analisis regresi linear sederhana sering dipergunakan dalam hal mengetahui pengaruh antara satu variabel penelitian dengan satu variabel yang berbeda.Adapun model perumusan dari Analisis sebagai berikut:

Keterangan:

$$
\mathrm{Y}=\beta_{0}+\beta_{1} \boldsymbol{X}+\varepsilon
$$

Y : variabel respon

$\mathrm{X} \quad$ : variabel prediktor

$\beta_{0} \quad$ : Nilai Konstanta yang merupakan titik potong regresi

$\beta_{1} \quad$ : Koefisien arah 
Fatimah, Hanif, Muhammad, Taufiqur, Yusril

Pengaruh Kualitas Pelayanan Terhadap Kepuasan Nasabah PT Pegadaian Area

Surabaya 2

Jurnal MANOVA Volume IV Nomor 1, P ISSN : 2685-4716, E ISSN : 2746-282X

\section{Hasil Temuan dan Pembahasan}

\section{Uji Validitas}

a. Hasil Uji Validitas X yakni kualitas pelayanan dari keseluruhan butir pertanyaan yang berjumlah 15 memiliki Nilai $r$ Hitung $>r$ tabel yang sebesar 0,195 jika jumlah sebaran Responden sebanyak 100 Orang. Artinya seluruh pertanyaan dinyatakan valid.

b. Hasil Uji Validitas Y yakni kepuasan pelanggan dari keseluruhan butir pertanyaan yang berjumlah 10 mempunyai Nilai $r$ hitung $>r$ tabel dengan tingkat taraf signifikansi 0,195 artinya seluruh butir pertanyaan dinyatakan valid.

\section{Uji Normalitas}

Uji normalitas adalah uji yang digunakan untuk mengetahui apakah nilai residual berdistribusi normal atau tidak. Model regresi yang baik adalah nilai residual yang terdistribusi normal. Uji yang digunakan adalah kolmogrof sminrov dengan nilai signifikansi 0,05 jika nilai signifikansi > 0,05 maka nilai residul terdistribusi normal dan jika nilai signifikansi $<0,05$ maka nilai residual tidak terdistribusi normal.

Tabel 1. Uji normalitas

One-Sample Kolmogorov-Smirnov Test

\begin{tabular}{|c|c|c|}
\hline & & $\frac{\text { Unstandardiz }}{\text { ed Residual }}$ \\
\hline$\underline{N}$ & & 100 \\
\hline \multirow[t]{2}{*}{ Normal Parameters ${ }^{\mathrm{a}, \mathrm{b}}$} & Mean & .0000000 \\
\hline & $\begin{array}{l}\text { Std. } \\
\text { Deviation }\end{array}$ & $\underline{8.46161923}$ \\
\hline Most Extreme & Absolute & .212 \\
\hline \multirow[t]{2}{*}{ Differences } & Positive & .212 \\
\hline & Negative & $\underline{-.078}$ \\
\hline Test Statistic & & .212 \\
\hline Asymp. Sig. (2-tailed) & &.$\overline{780^{\circ}}$ \\
\hline
\end{tabular}
A. Test distribution is Normal.
B. Calculated from data.
C. Lilliefors Significance Correction.

Sumber : pengolahan Data SPSS Versi 25.0

Berdasarkan tabel 2 diatas dapat diketahui bahwa nilai hasil uji normalitas menunjukkan nilai signifikansi sebesar 0,780 yang artinya lebih besar dan dapat disimpulkan data terdistribusi normal. 
Fatimah, Hanif, Muhammad, Taufiqur, Yusril

Pengaruh Kualitas Pelayanan Terhadap Kepuasan Nasabah PT Pegadaian Area

Surabaya 2

Jurnal MANOVA Volume IV Nomor 1, P ISSN : 2685-4716, E ISSN : 2746-282X

\section{Uji Reliabilitas}

Berdasarkan uji reliabilitas data variabel Total X dan Y dikatakan variabel itu reliabilitas jika uji reabilitas Cronbach Alpha >0,6 menurut wiranta Sujarweni (2004) dengan rincian hasil sebagai berikut:

Tabel 2. Hasil reabilitas Total Variabel X dan Y

\section{Reliability Statistics}

\begin{tabular}{r|ll}
$\begin{array}{c}\text { Cronbach's } \\
\text { Alpha }\end{array}$ & N of Items & \\
\hline .614 & 2
\end{tabular}

Sumber : Pengolahan Data Spss Versi 25.0

Dari hasil tabel tersebut jumlah dinyatakan bahwa seluruh instrumen yang ada pada seluruh variabel dinyatakan reliable karena nilai cronbanch alfa lebih besar dari 0,60 .

\section{Uji Heterokedasitas}

Uji heteroskedastisitas digunakan untuk mengetahui ada atau tidaknya ketidaksamaan varian dan residual dalam model regresi yang digunakan hasil uji ini dapat diketahui dengan melihat signifikansinya . Apabila lebih besar dari 0,05 maka dapat disumpulkan tidak terjadi heterokedastisitas berikut ini hasil uji heterokedastisitas. :

Tabel 3. Uji Heteroskedastisitas

\begin{tabular}{|c|c|c|c|c|c|}
\hline \multicolumn{6}{|c|}{ Coefficients $^{a}$} \\
\hline \multirow[b]{2}{*}{ Model } & \multicolumn{2}{|c|}{$\begin{array}{l}\text { Unstandardized } \\
\text { Coefficients }\end{array}$} & \multirow{2}{*}{$\begin{array}{c}\text { Standardized } \\
\text { Coefficients } \\
\text { Beta } \\
\end{array}$} & \multirow[b]{2}{*}{$\mathrm{T}$} & \multirow[b]{2}{*}{ Sig. } \\
\hline & $\mathrm{B}$ & Std. Error & & & \\
\hline (Constant) & 6.240 & 18.542 & & .337 & .737 \\
\hline $\begin{array}{l}\text { Kualitas } \\
\text { layanan }\end{array}$ & .015 & .253 & .006 & .059 & .953 \\
\hline
\end{tabular}

A. Dependent Variable: Abs_Res

Berdasarkan pada tabel 3 bahwa kualitas pelayanan memiliki nilai signifikansi diatas 0,05 yakni sebesar 0,953 yang artinya dalam penelitian ini tidak terdapat gejala heterokedastisitas. 
Fatimah, Hanif, Muhammad, Taufiqur, Yusril

Pengaruh Kualitas Pelayanan Terhadap Kepuasan Nasabah PT Pegadaian Area

\section{Uji Regresi Linear Sederhana}

Tabel 4.Uji Regresi Linear Sederhana

\begin{tabular}{|c|c|c|c|c|c|c|}
\hline \multirow[b]{4}{*}{ Model } & \multicolumn{6}{|c|}{ Coefficients $^{\mathrm{a}}$} \\
\hline & & \multicolumn{2}{|c|}{ Unstandardized } & \multirow{2}{*}{$\begin{array}{l}\text { Standardized } \\
\text { Coefficients }\end{array}$} & \multirow[b]{3}{*}{$\mathrm{T}$} & \multirow[b]{3}{*}{ Sig } \\
\hline & & \multicolumn{2}{|c|}{ Coefficients } & & & \\
\hline & & B & Std. Error & Beta & & \\
\hline 1 & (Constant) & 14.697 & 6.913 & & 2.126 & .036 \\
\hline & Kualitas Layanan & .462 & .094 & .443 & 4.898 & .000 \\
\hline
\end{tabular}

Dependent Variable: Kepuasan

Sumber : Pengolahan Data SPSS Versi 25.0

Uji regresi linear sederhana dapat dilakukan dengan beberapa pembuktian hipotesis penelitian sebagai berikut :

1) $H_{0}: \mathrm{Sig}>\alpha$, tidak ditemukan pengaruh variabel kulaitas pelayanan (X) terhadap Kepuasan Nasabah (Y)

2) $H_{a}: \mathrm{Sig}<\alpha$ ada pengaruh variabel kualitas pelayanan (X) terhadap kepuasan nasabah.

Berdasarkan hasil analisis data diketahui bahwa tingkat signifikansi variabel kualitas pelayanan signifikansi positif sebesar $=0,00<0,05$. Karena nilai $\mathrm{p}<0,05$ maka $H_{0}$ ditolak dan $H_{a}$ dinyatakan diterima. Yang berarti terdapat pengaruh positif kaulitas pelayanan terhadap kepuasan nasabah.

\section{Uji Determinasi}

Tabel 5 Uji Determinasi Model Summary

\begin{tabular}{|c|c|c|c|c|}
\hline \multicolumn{5}{|c|}{ Model Summary } \\
\hline Model & $\mathrm{R}$ & R Square & $\begin{array}{l}\text { Adjusted } \mathrm{R} \\
\text { Square }\end{array}$ & $\begin{array}{l}\text { Std. Error of } \\
\text { the Estimate }\end{array}$ \\
\hline 1 & $.443^{\mathrm{a}}$ & .197 & .188 & 1.560 \\
\hline
\end{tabular}

A. Predictors: (Constant), Kualitas Layanan

B. Dependent Variable: Kepuasan

Sumber Pengolahan Data SPSS Versi 25

Dari hasil perhitungan diatas diketahui bahwa nilai koefisien determinasi adalah sebesar 0,197 dimana 19,7\% kepuasan nasabah dipengaruhi oleh kualitas pelayanan sementara sisanya $81 \%$ dipengaruhi oleh faktor lain yang dapat dijelaskan oleh variabel diluar dari kualitas layanan. 
Fatimah, Hanif, Muhammad, Taufiqur, Yusril

Pengaruh Kualitas Pelayanan Terhadap Kepuasan Nasabah PT Pegadaian Area

Jurnal MANOVA Volume IV Nomor 1, P ISSN : 2685-4716, E ISSN : 2746-282X

\section{Kesimpulan}

PT. Pegadaian (Persero) Area Surabaya 2 merupakan lembaga keuangan non bank yang berada dalam pengawasan kementerian keuangan Republik Indonesia yang dimana menyediakan produk atau jasa berupa pinjaman dana berupa kredit kepada nasabah dan menerima jaminan berupa barang sebagai gantinya yang akan dikembalikan jika nasabah dapat melunasi hutang selama periode pinjaman berlangsung. Namun jika nasabah tidak dapat melunasi hutangnya maka barang akan dilelang dan sisa hasil lelang akan dikembalikan kepada nasabah, tetapi jika hasil lelang masih kurang untuk membayar hutang maka nasabah wajib membayar kekurangannya. Dimana salah satu hal yang terpenting dalam perusahaan jasa seperti pegadaian adalah kualitas pelayanan yang diberikan kepada nasabah guna memperoleh kepuasan pelanggan secara maksimal karena dapat berdampak jangka panjang terhadap keberlangsungan dan eksistensi pegadaian.

Hasil uji hipotesis dapat disimpulkan bahwa terdapat hubungan yang signifikan antara kualitas pelayanan terhadap kepuasan nasabah PT. Pegadaian (Persero) area Surabaya 2. Dimana hal ini dibuktikan dengan dengan nilai signifikasi Uji T sebesar 0,000 $<0,05$ karena nilai $\mathrm{p}<0,05$ makan Ho ditolak dan Ha diterima. Serta hasil dari Uji F yang menunjukkan $\mathrm{F}$ hitung $(23,992)$ dengan nilai signifikansi sebesar $0,000<0,05$. Dengan demikian terdapat hubungan yang signifikan antara kualitas pelayanan terhadap kepuasan nasabah PT. Pegadaian (Persero) area Surabaya 2.

\section{Saran}

Pada aspek bukti fisik (Tangible) perlu adanya peningkatan kebrsihan dalam ruang tunggu nasabah dan lebih menjaga kebersihan toilet seperti memberikan pewangi atau sejenisnya. Pada aspek daya tanggap (Responsive) Perlu adanya peningkatan terhadap penanganan keluhan nasabah dan pemberian informasi yang jelas, dikarenakan masih banyak keluhan yang disampaikan oleh nasabah seperti kurangnya informasi baik itu berupa pelelangan barang dan ketika nasabah tidak dapat memenuhi hutang yang dijanjikan dalam kurun waktu tertentu. Serta perlu adanya apresiasi untuk nasabah lama dan baru agar dibedakan supaya para nasabah dapat meningkatkan loyalitasnya melakukan transasksi di PT. Pegadaian (Persero) area Surabaya 2. 
Fatimah, Hanif, Muhammad, Taufiqur, Yusril

Pengaruh Kualitas Pelayanan Terhadap Kepuasan Nasabah PT Pegadaian Area

Surabaya 2

Jurnal MANOVA Volume IV Nomor 1, P ISSN : 2685-4716, E ISSN : 2746-282X

\section{DAFTAR PUSTAKA}

Kotler, Philip. (2003). Manajemen Pemasaran. Jakarta: Penerbit Prenhallindo.

Kotler dan Amstrong. (2001). Prinsip-Prinsip Pemasaran Edisi Keduabelas Jilid 1. Jakarta: Penerbit Erlangga.

Lupiyoadi, Rambat dan Hamdani. (2006). Manajemen Pemasaran Jasa Edisi Kedua. Jakarta: Penerbit Salemba Empat.

Suparlan. (2000). Asas Manajemen. Jakarta: Penerbit Salemba Empat.

Tjiptono, Fandy. (2008). Strategi Pemasaran. Yogyakarta: Penerbit ANDI.

Wahab, Wardayani. (2017). Pengaruh Kualitas Pelayanan Terhadap Kepuasan NasabahPegadaian Syariah di Kota Pekanbaru. Riau: Jurnal Lembaga Keuangan dan Perbankan, Volume 2 Nomor 1 STIE Mahaputra Riau. 